\title{
Predation affects alarm call usage in female Diana monkeys (Cercopithecus diana diana)
}

\author{
Claudia Stephan • Klaus Zuberbühler
}

Received: 15 August 2013 /Revised: 17 October 2013 / Accepted: 18 October 2013 /Published online: 8 November 2013

(C) Springer-Verlag Berlin Heidelberg 2013

\begin{abstract}
Diana monkeys produce acoustically distinct calls to a number of external events, including different types of predators. In a previous study, we found population-wide differences in male alarm call production in Taï Forest, Ivory Coast, and on Tiwai Island, Sierra Leone, mostly likely originating from differences in predator experience. In Taï Forest, leopards (Panthera pardus) are common but on Tiwai Island they have been absent for decades, while the predation pressure from crowned eagles (Stephanoaetus coronatus) has been similar. To further evaluate the impact of predator experience, we here analyse the vocal behaviour of female Diana monkeys in both habitats. Female Diana monkeys produce predatorspecific alarm calls, alert calls and contact calls in response to predators, suggesting that their calls serve in a broader range of functions compared to males. Results showed that females produced the same call types at both sites, despite the differences in predator fauna. Regarding call usage, leopard alarm calls were extremely rare on Tiwai Island, but not in Taï Forest, whereas we found no differences in eagle alarm call production. When comparing response latencies, Tiwai females were slower to respond to both predators compared to Taï females.
\end{abstract}

Communicated by D. P. Watts

C. Stephan $\cdot$ K. Zuberbühler

School of Psychology and Neuroscience, University of St Andrews, St Andrews, Scotland, UK

K. Zuberbühler

e-mail: kz3@st-andrews.ac.uk

C. Stephan

Department of Cognitive Biology, University of Vienna, Vienna, Austria

C. Stephan $(\varangle) \cdot K$. Zuberbühler

Department of Comparative Cognition, Institute of Biology,

University of Neuchâtel, Rue Emile-Argand 11, 2000 Neuchâtel, Switzerland

e-mail: clamoretgaudium@gmx.net
Finally, we found no habitat-specific acoustic differences in the alert and predator-specific alarm calls, but significant differences in frequency-based parameters of contact calls. Overall, our results suggest that ontogenetic experience can affect primate vocal behaviour in both usage and acoustic structure but that the way in which particular call types are affected may be closely linked to function.

Keywords Vocal flexibility · Vocal development · Predation . Predator-specific alarm calls $\cdot$ Predator absence

\section{Introduction}

Flexibility in vocal production and comprehension are key components of the generative power of human language (e.g., Fitch 2005). The evolutionary origins of this flexibility are the focus of much comparative research. In many taxa, the evidence for flexibility is better for comprehension than production (birds: Stephan and Bugnyar 2013; mammals: Townsend et al. 2011). For signal production, the evidence is comparably scarce, especially in primates (e.g., Winter et al. 1973; Owren et al. 1993; Snowdon 2009). One interpretation has been that comprehension and production are caused by different cognitive abilities (Seyfarth and Cheney 2003). A related finding is that in many birds and most mammals there is almost no evidence for vocal learning in the sense that young individuals acquire their communicative competence from interacting with older individuals (Seyfarth and Cheney 1986). Only a small number of species are capable of imitating arbitrary acoustic structures and usually this involves sound production mechanisms other than larynx (elephants: Poole et al. 2005; Stoeger et al. 2012; marine mammals: Janik and Slater 1997; Schustermann 2008; Fitch 2010).

Given this widespread lack of flexibility in vocal production across the animal kingdom, how did humans evolve such a high degree of vocal control? A productive way to address 
this question has been to discriminate between different levels of control, notably over signal structure and usage (Janik and Slater 2000; Seyfarth et al. 2005). Although there is some empirical evidence for signal modification and behavioural context in which signals are uttered, the role of ontogenetic experience under natural conditions remains unclear. Early research on vervet monkeys has shown that in primates the acquisition of context-specific signalling is partially driven by experience, with infants learning to deploy some of their call types to relevant external events (e.g., Seyfarth and Cheney 1986). However, ontogenetic studies of vocal behaviour are notoriously difficult to carry out, especially under natural conditions, and correspondingly little progress has been made in this area of investigation. An alternative approach is to study the vocal behaviour of adult individuals that have grown up in different environments. We have chosen this approach with a comparative study between two natural habitats of Diana monkeys, the Taï Forest, Ivory Coast, and Tiwai Island, Sierra Leone.

In forest guenons (Cercopithecus spp.), a peculiar finding has been that most species show a remarkable sexual dimorphism in their call repertoire and use. Most species live in groups with only one reproductively active male, who is often spatially and socially separated from other group members (Bshary and Noë 1997; Buzzard and Eckardt 2007; Todd et al. 2008; Bouchet et al. 2012). Male vocal behaviour is mainly restricted to loud alarm calling given to a range of events, mostly some sort of disturbance (Rowell 1988). These calls are low-pitched and carry over considerable distances (e.g., $>800 \mathrm{~m}$ for $C$. diana; KZ, unpublished data). Guenon longdistance calls are thought to be multi-functional, serving in predator avoidance and male-male competition over access to females (Zuberbühler 2002). Hence, sexual selection is likely to have affected male calling behaviour, in support of their general strive to maintain tenure and keep away solitary rival males seeking to acquire their own group (Wich and Nunn 2002; Zuberbühler 2002). For several species, it has also been shown that male loud calls convey information about external events, particularly the type of predator that has been encountered (Arnold and Zuberbühler 2006), its location (Zuberbühler 2000a), the identity of the caller (Lemasson et al. 2010), the caller's intention to move (Arnold and Zuberbühler 2008), or the distance to the predator (Papworth et al. 2008; Murphy et al. 2013).

In a previous study, we found population differences in the sequencing of male Diana monkey loud alarm calls that appeared to have emerged from habitat differences (Stephan and Zuberbühler 2008). Monkeys living in Taï Forest produced sequences with fewer call units per sequence to leopards compared to males living on Tiwai Island. In contrast, no major differences were found in the males' responses to crowned eagles, another major predator. The most plausible explanation for these differences is that, although the two habitats are largely identical, they differ in the presence or absence of leopards, while crowned eagles can be found at both sites.

In the present study, we focus on the vocal behaviour of adult female Diana monkeys, which is considerably more diverse than the males' and contains calls that function in group cohesion and contact with other group members, coordination of group movements, social interactions, and predator avoidance (Hill 1994; Zuberbühler et al. 1997; Zuberbühler 2000a, b). In contrast to males, female calls are mainly close-range signals (e.g., Uster and Zuberbühler 2001) with a complex structural organisation. For instance, contact calls are composed of various subunits, which are assembled in rule-governed ways (Candiotti et al. 2012a), possibly to facilitate individual recognition in a visually difficult habitat and to convey information about the external event experienced by the caller (Candiotti et al. 2012b). Given our previous finding in males (Stephan and Zuberbühler 2008), we were interested in the effects of predation on the alarm calling behaviour of adult females on Tiwai Island and in the Taï Forest.

\section{Methods}

\section{Study subjects}

We recorded vocal responses of a large number of Diana monkey groups to different playback stimuli on Tiwai Island $\left(N_{\text {Tiwai }}=13\right.$; February to May 2007$)$ and in Taï Forest $\left(N_{\text {Taï }}=\right.$ 30; July 1994, June 1995, July to November 1996, January to June 1997 and February 2000). Group compositions were comparable at both study sites, consisting of one reproductive male, 8-13 adult females and several juveniles and infants resulting in 15-25 group members (Oates et al. 1990; Buzzard and Eckardt 2007). Average home range sizes have been estimated at around $0.5 \mathrm{~km}^{2} /$ group at both sites (Höner et al. 1997; Whitesides et al. 1988). None of the groups were habituated to human observers, so we selected study groups from a larger pool of around 50 groups in Taï encountered over an area of about $100 \mathrm{~km}^{2}$ and of around 15-20 groups on Tiwai. Individual identification of subjects was not possible but different groups could be distinguished, mostly by their location.

\section{Experimental procedure}

Every group was only tested once with a particular playback stimulus. All playback experiments were carried out following an established protocol (Zuberbühler et al. 1997). Briefly, the experimenter (Tiwai: CS; Taï: KZ) searched the forest for monkey groups, locating them via auditory cues and silently approaching them to a distance of approximately $20 \mathrm{~m}$ 
without being detected. Subsequently, the recording and playback equipment was positioned, followed by an observational period of at least 20 min during which the group's behaviour was recorded. Additionally, we noted all unusual events that were likely to impact on subjects' responses, such as the appearance of large terrestrial mammals (e.g., bushbuck, duiker), encounters with a neighbouring Diana monkey group, other monkey species, or chimpanzees. These trials were not used for subsequent analyses. We also estimated the approximate distance of the male from the group and the group size before each playback experiment. If no disturbing event occurred, we recorded the group's vocal behaviour for at least $3 \mathrm{~min}$, after which a playback stimulus was broadcasted and the monkeys' vocal responses recorded for at least $10 \mathrm{~min}$. Playback stimuli consisted of $15 \mathrm{~s}$ of crowned eagle shrieks $(N=3$ playback stimuli), leopard growls $(N=3$ playback stimuli), male Diana monkey eagle ( $N=3$ playback stimuli) or leopard alarm calls ( $N=3$ playback stimuli), respectively.

On Tiwai Island, playback stimuli were stored digitally and broadcasted with a portable CD player connected to a Nagra DSM speaker-amplifier. Vocal responses were recorded using a Sony WM-D6C recorder and a Sennheiser ME80 directional microphone. At Taï, the playback stimuli were broadcasted using a Sony WM-D6C professional Walkman, connected to a Nagra DSM speaker-amplifier, while the vocal responses were recorded with a Sennheiser ME80 microphone and a Sony TCM-3000 cassette recorder.

Following a playback trial, the area described by a radius of at least $500 \mathrm{~m}$ surrounding the playback location was avoided for further experiments with the same stimulus for at least 2 weeks to prevent any impact of playbacks on future responses of neighbouring groups, in case they might have heard the playback stimulus or the target group's vocal response to it. We excluded trials from further analysis if (1) the location of the focal male was unknown, (2) more than one Diana monkey group responded to playback and (3) technical problems or environmental noise prevented an acceptable recording quality.

\section{Call analysis}

All recordings were digitised using COOL EDIT 2000 (Syntrillium Software Corporation, Phoenix, AZ, USA) and analysed with PRAAT (5.1.29). We only analysed the first minute of each vocal response following the beginning of a playback stimulus, assuming that predator-specific vocal behaviour should emerge immediately. Diana monkeys generally prefer to forage in the upper forest canopy (McGraw 2007), which prevented us from collecting data from individual females. We therefore analysed the vocal response at the group level. Although this is not ideal, group sizes were similar between habitats and from observations on habituated groups it emerged that predator-specific alarm calls were usually only given by $1-2$ adult females.

To investigate the differences in the vocal behaviour of Taï and Tiwai females, we extracted several acoustic parameters from our collection of recorded calls $\left(N_{\text {Tiwai }}=105, N_{\text {Tai }}=145\right.$, after removing all calls with interfering background noise). We used a customised programme in the PRAAT DSP package (settings: time step: $0.01 \mathrm{~s}$; expected $\mathrm{F} 0$ frequency range: $300-4,000 \mathrm{~Hz}$ ), with an automatic logger in an output file. The following frequency parameters were measured: (a) mean fundamental frequency (mean_F0; Hz), (b) maximum and minimum fundamental frequency (max_F0 and min_F0; $\mathrm{Hz}$ ), (c) range of fundamental frequency (range_F0, Hz), (d) fundamental frequency at the beginning, middle and end of a call (start_F0, mid_F0, end_F0; Hz). Furthermore, the following temporal parameters were extracted: (e) time of maximum and minimum fundamental frequency (tF0_max and tF0_min; s) and (f) time at the beginning and end of fundamental frequency. From the latter, the duration of all calls was calculated (call length; s), resulting in ten acoustic parameters for each call that entered the subsequent classification analysis.

Furthermore, the latency of vocal responses was measured, which was defined as the time that passed from the beginning of a playback to the first call given by any of the group's females.

\section{Statistical analysis}

In order to compare acoustic features of call types recorded in Taï and on Tiwai, we first conducted two Discriminant Function Analyses (DFA). Each call was categorised in term of its 'habitat' and 'type' as the group identifier. We further analysed potential differences in classification accuracy within single call types, using 'habitat' as the group binding variable for each of the four female call types (contact calls, alert calls, leopard alarm calls, eagle alarm calls) (Fig. 1). This served to clarify whether habitat-specific differences in the vocal repertoire were a general phenomenon or only found for particular call types. Because of the uneven distribution of recorded calls between habitats and call types, prior probabilities were calculated on the basis of group size (either on the number of calls for each habitat or on the number of calls for each call type). We used the reclassification method and the more conservative leave-one-out cross-validation procedure and assessed statistical significance of correct classification by means of Wilks' lambda values, $F$ values and two-tailed probabilities (significance levels: $p=0.05$ ). DFA was conducted using SPSS v. 20.

To evaluate the effect of the playback stimulus, the habitat and the interaction between the two factors on the latency of female responses, we analysed the variable 'latency to call' using a generalized linear mixed model (GLMM) with Gaussian error distribution and an identity-link function with the variables 'habitat' and 'playback stimulus' as fixed factors. To control for group differences, we included 'group' as a 
Fig. 1 Spectrograms for female a alert calls, b contact calls, $\mathbf{c}$ leopard alarm calls and $\mathbf{d}$ eagle alarm calls at Tiwai Island and in Taï forest a

Tiwai

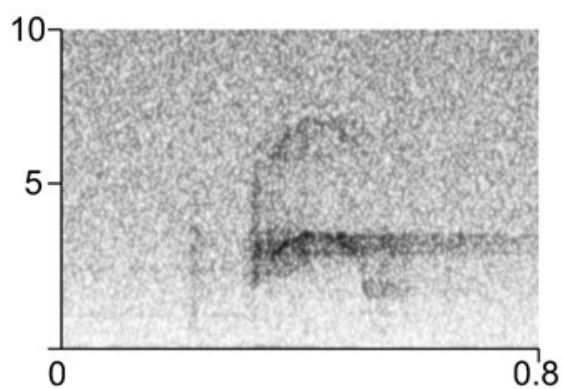

b

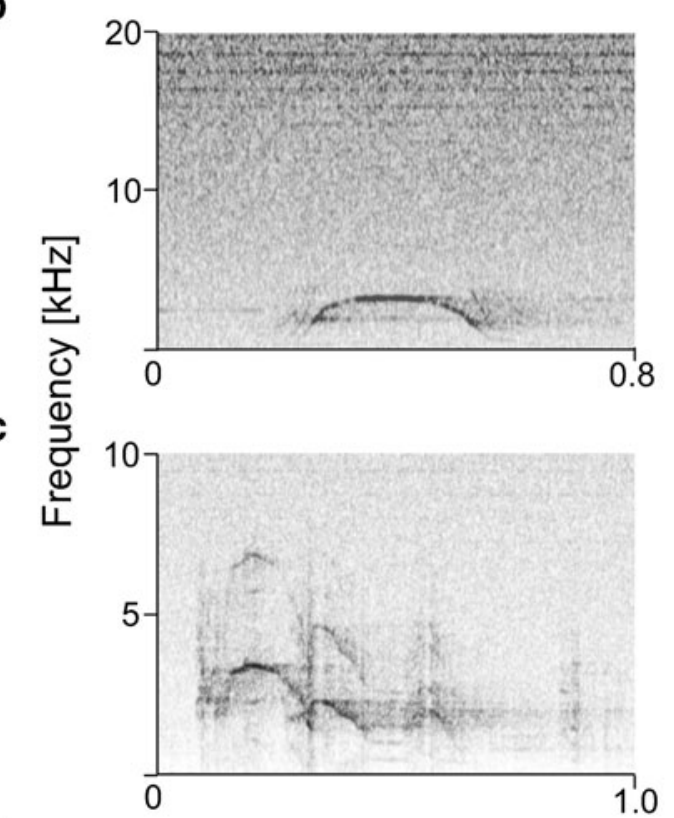

d

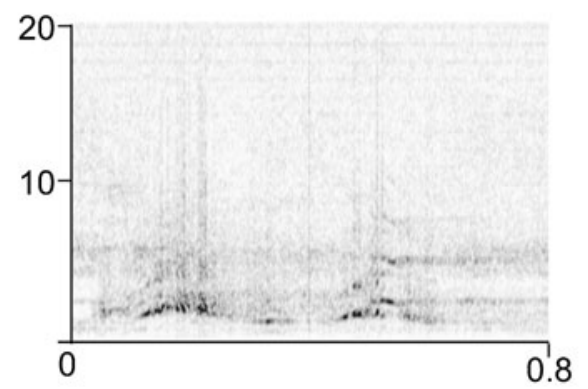

Taï
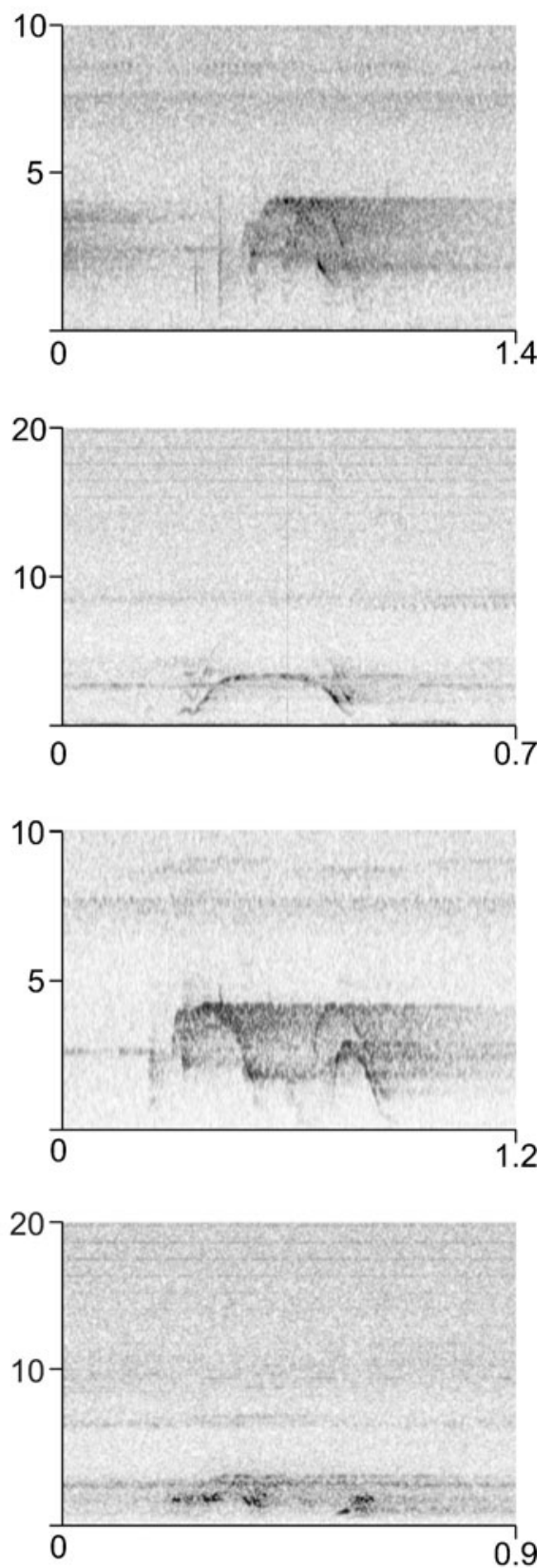

\section{Time [sec]}

random factor. Additionally, we included a Bonferroni correction $(\alpha<0.0125)$ to control for repeated pairwise comparisons of latencies to call within each habitat. Corrected Akaike's information criteria (AICc) values were compared to select the most parsimonious model with the lowest $\mathrm{AICc}$ value using the AICcmodavg package and to control that both factors impacted on data distribution. The best-fit model included both fixed factors ('habitat' and 'playback', $\mathrm{AICc}=381.489$ ) whereas both models including only one fixed factor resulted in higher AICc values (with 'habitat' $\mathrm{AICc}=412.748$; with 'playback' $\mathrm{AICc}=422.496$ ), thus confirming the contribution of both included factors on data distribution. To compare female responses between habitats, we compared the 'latencies to call' and call composition of vocal responses for each playback type including call numbers in the first minute after broadcasting each playback stimulus using non-parametric statistics (two-tailed Mann-Whitney $U$-tests). These analyses were conducted using R v. 2.14.1. 


\section{Results}

\section{Call repertoire}

When analysing habitat-specific differences within particular call types, we found no differences in the frequency and temporal features of predator-specific alarm calls and alert calls across habitats, but consistent differences in acoustic features of females' contact calls between Tiwai and Taï.

The extracted calls were classified more accurately by using 'call type' as the class-defining factor than they were with 'habitat' being the group identifier. In particular, the DFA classified $62.2 \%$ of cases correctly with 'habitat' defining group membership (dropping to $58.4 \%$ when the more conservative leave-one-out cross validation was used). Compared to this, group membership was correctly predicted in $78.7 \%$ of cases if using 'call type' as group identifier (dropping to $76.5 \%$ when the more conservative leave-one-out cross validation was used). Differences in acoustic parameters of calls could not be confirmed with 'habitat' as group identifier for any of the extracted parameters (Table 1). One discriminant function was identified with this group identifier on which max_F0 (maximum fundamental frequency), range_F0 (range of fundamental frequency), tF0 min (time of minimal fundamental frequency), mid_F0 (fundamental frequency in the middle of the call) and start_F0 (fundamental frequency at the onset of call) loaded most (Table 2). High values for Wilks' lambda (Wilks' $\lambda=0.931$ ) and associated nonsignificant values $(p=0.102)$ further confirmed that groups' means did not differ according to 'habitat' in discriminant function 1 . In contrast, there were significant differences in all acoustic parameters except frequency range when 'call type' was the group identifier (Table 3). Comparing the groups' means by the discriminative feature 'call type' revealed three discriminant functions that were used for analysis (for different contributions of call parameters on each discriminant function see Table 4). Hence, 'call type' rather than 'habitat' explained a greater proportion of the variation in acoustic features among extracted calls.

To further investigate differences between habitats within single call types, we conducted additional DFA with 'habitat' as group identifier for each call type separately. Surprisingly, classification accuracy was low for all call types except for contact calls (conservative leave-one-out cross validation for alert calls: $50.3 \%$, leopard alarm calls: $58.3 \%$, eagle alarm calls: $57.1 \%$, contact calls: $88.9 \%$ ), indicating that acoustic parameters of specific call types did not differ between Taï and Tiwai with the exception of contact calls (see Table 5 for details on significant differences in acoustic parameters between groups' means).

\section{Call rates}

\section{Habitat-specific differences in call type presence}

Eagle-related stimuli (eagle shrieks and male Diana eagle alarms) consistently triggered the females' own eagle alarm calls in addition to contact calls and general alert calls in Taï (eagle shrieks: eight of 11 groups; eagle alarms: ten of ten groups) and on Tiwai (eagle shrieks in seven of seven groups; eagle alarms: five of six groups). The proportion of groups uttering at least one eagle alarm call and those that did not utter any eagle alarm call to eagle-related playbacks did not differ between habitats (Fisher's exact text: to eagle shrieks: $p=$ 0.2451; to eagle alarms: $p=0.3333$ ).

Leopard-related stimuli (leopard growls and male Diana leopard alarms) reliably triggered alert calls in Taï (leopard growls: 13 of 13 groups; leopard alarms: nine of nine groups) and on Tiwai (leopard growls: 11 of 11 groups; leopard alarms: seven of seven groups). The two habitats did not differ in the frequency of alert call production (Fisher's exact text: to
Table 1 Descriptive statistics and tests of equality of groups' means for 'habitats' as group identifier for all acoustic parameters that have been included in the Discriminant Function Analysis

\begin{tabular}{|c|c|c|c|c|c|c|c|}
\hline & \multicolumn{2}{|l|}{ Mean } & \multicolumn{2}{|l|}{$\mathrm{SD}$} & \multirow[t]{2}{*}{ Wilks' $\lambda$} & \multirow[t]{2}{*}{$F_{1,228}$} & \multirow[t]{2}{*}{$p$} \\
\hline & Tiwai & Таї & Tiwai & Таї & & & \\
\hline mean_F0 & 2606.2 & 2543.9 & 679.3 & 770.1 & 0.998 & 0.381 & 0.537 \\
\hline max_F0 & 3397.3 & 3191.4 & 751.4 & 768.4 & 0.983 & 3.909 & 0.059 \\
\hline min_F0 & 1732.1 & 1702.2 & 736.4 & 805.2 & 1 & 0.78 & 0.78 \\
\hline range_F0 & 1669.6 & 1489.2 & 895.7 & 830.4 & 0.988 & 2.657 & 0.104 \\
\hline start_F0 & 2357.69 & 2208.6 & 868.2 & 863.5 & 0.993 & 1.588 & 0.209 \\
\hline mid_F0 & 2881.6 & 2281.5 & 816.9 & 841.5 & 1 & 0.034 & 0.854 \\
\hline end_F0 & 2302.4 & 2705.9 & 874.1 & 973.9 & 0.992 & 1.878 & 0.172 \\
\hline tF0_max & 0.15 & 0.15 & 0.07 & 0.1 & 1 & 0.013 & 0.909 \\
\hline tF0_min & 0.16 & 0.14 & 0.12 & 0.13 & 0.991 & 1.959 & 0.163 \\
\hline call length & 0.24 & 0.24 & 0.13 & 0.15 & 1 & 0.043 & 0.835 \\
\hline
\end{tabular}


Table 2 DFA structure matrix representing pooled within-groups correlations between discriminating variables and the standardized canonical discriminant functions that entered analysis for 'habitat' being the group identifier

\begin{tabular}{lc}
\hline & Discriminant function 1 \\
\hline max_F0 & 0.481 \\
range_F0 & 0.397 \\
tF0_mid & 0.341 \\
mid_F0 & 0.334 \\
start_F0 & 0.307 \\
mean_F0 & 0.15 \\
min_F0 & 0.068 \\
call_length & 0.051 \\
end_F0 & 0.045 \\
tF0_max & -0.028 \\
\hline
\end{tabular}

The variables are ordered by absolute size of correlation within function. The extracted discriminant function(s) accounted for $100 \%$ of the variance

leopard growls: $p=1$; to leopard alarms: $p=1$ ). Leopard alarm calls, however, were common in Taï (leopard growls: 12 of 13 groups; leopard alarms: in nine of nine groups) but uncommon on Tiwai (leopard growls: five of 11 groups; leopard alarms: three of seven groups). The probability of females producing at least one leopard alarm call to leopard-related stimuli was significantly lower on Tiwai than in Taï (Fisher's exact text: to leopard growls: $p=0.0018$; to leopard alarms: $p=0.019$ ).

\section{Habitat-specific differences in call numbers}

There were significant inter-site differences in the number of calls uttered during the first minute of playbacks (Fig. 2). To leopard growls, Taï females produced significantly more leopard alarm calls and significantly more alert calls than Tiwai females (median leopard alarms: Taï: 7 vs. Tiwai: 0; median alert calls: Taï: 47 vs. Tiwai: 32; Table 6). The same pattern was observed for vocal responses to playbacks of male leopard alarm calls (median leopard alarms: Taï: 6 vs. Tiwai: 0; median alert calls: Taï: 67 vs. Tiwai: 21.5 ). To eagle shrieks, Taï females produced significantly more alert calls but not significantly more eagle alarm calls than Tiwai females (median eagle alarms: Taï: 5.5 vs. Tiwai: 8 ; median alert calls: Taï: 9 vs. Tiwai: 1; Table 6). To male Diana eagle alarm calls, there were no differences in the number of eagle alarms and alert calls between the two study sites. Contact calls did not differ between sites in any of the four playback conditions (Table 6).

\section{Latencies of vocal responses}

To assess differences in perceived urgency and threat we also compared how fast females responded to the different playbacks. Females in both habitats responded rapidly to the different playback types, although there was a significant interaction between playback stimulus and study site on response latency (GLMM: $F_{3,66}=8.403, p<0.0001$; Fig. 3). Taï females responded faster than Tiwai females to all playback stimuli except for leopard alarm calls (Mann-Whitney $U$-tests; Table 7). Afterwards, we split the original data set according to the significant interaction between call type and habitat and analysed the impact of playback type on the latency of female responses for each habitat separately. The latency to respond varied significantly according to playback type on Tiwai Island (GLMM: $F_{3,27}=4.063, p=0.0101$ ) but not in Taï Forest (GLMM: $F_{3,39}=1.754, p=0.1719$ ).

In particular, although females on Tiwai have not previously encountered leopards, they responded faster to leopard-

Table 3 Descriptive statistics and tests of equality of groups' means for 'call type' being the group identifier for all acoustic parameters that have been included in the Discriminant Function Analysis

\begin{tabular}{|c|c|c|c|c|c|c|c|c|c|c|c|}
\hline & \multicolumn{4}{|l|}{ Mean } & \multicolumn{4}{|l|}{$\mathrm{SD}$} & \multirow[t]{2}{*}{ Wilks' $\lambda$} & \multirow[t]{2}{*}{$F_{1,226}$} & \multirow[t]{2}{*}{$p$} \\
\hline & Contact call & Alert call & Leopard alarm & Eagle alarm & Contact call & Alert call & Leopard alarm & Eagle alarm & & & \\
\hline mean_F0 & 2644.6 & 2869.6 & 2102.5 & 1009.8 & 558.2 & 462.8 & 624.7 & 370.7 & 0.45 & 91.893 & $<0.001$ \\
\hline max_F0 & 3233.5 & 3557.8 & 2905.4 & 1958.2 & 573.6 & 510.1 & 822.5 & 939.8 & 0.627 & 44.801 & $<0.001$ \\
\hline min_F0 & 1788.6 & 1972.2 & 1308.3 & 366.6 & 574.7 & 712.4 & 409.6 & 160.5 & 0.632 & 43.824 & $<0.001$ \\
\hline range_F0 & 1458.4 & 1589.3 & 1597.1 & 1591.6 & 716.7 & 891.4 & 928.7 & 937.1 & 0.996 & 0.325 & 0.808 \\
\hline start_F0 & 2114.6 & 2618.8 & 1758.7 & 1008.9 & 709 & 725.7 & 712.8 & 639.8 & 0.669 & 37.282 & $<0.001$ \\
\hline mid_F0 & 2968.3 & 3106.1 & 1994.2 & 833.7 & 693.9 & 710.8 & 703.5 & 306.3 & 0.661 & 38.634 & $<0.001$ \\
\hline end_F0 & 2323.8 & 2555.9 & 2191.3 & 873.3 & 664.3 & 624.9 & 895 & 553.5 & 0.488 & 79.144 & $<0.001$ \\
\hline tF0_max & 0.13 & 0.14 & 0.26 & 0.14 & 0.05 & 0.05 & 0.18 & 0.12 & 0.845 & 13.818 & $<0.001$ \\
\hline tF0_min & 0.13 & 0.14 & 0.24 & 0.17 & 0.11 & 0.1 & 0.17 & 0.13 & 0.907 & 7.689 & $<0.001$ \\
\hline call length & 0.21 & 0.23 & 0.27 & 0.39 & 0.13 & 0.08 & 0.22 & 0.23 & 0.876 & 10.68 & $<0.001$ \\
\hline
\end{tabular}

Significant $p$ values are indicated in bold 
Table 4 DFA structure matrix representing pooled within-groups correlations between discriminating variables and the standardized canonical discriminant functions that entered analysis for 'call type' being the group identifier

\begin{tabular}{lcrr}
\hline & \multicolumn{2}{l}{ Discriminant function } \\
\cline { 2 - 4 } & 1 & 2 & \multicolumn{1}{c}{3} \\
\hline mean_F0 & $\mathbf{0 . 7 9 7}$ & 0.292 & -0.121 \\
mid_F0 & $\mathbf{0 . 7 3 9}$ & 0.267 & 0.186 \\
max_F0 & $\mathbf{0 . 5 5 2}$ & 0.184 & -0.396 \\
min_F0 & $\mathbf{0 . 5 5}$ & 0.204 & -0.059 \\
end_F0 & $\mathbf{0 . 5 2 2}$ & 0.101 & -0.156 \\
tF0_max & -0.05 & $-\mathbf{0 . 6 2 9}$ & -0.267 \\
start_F0 & 0.477 & 0.273 & $-\mathbf{0 . 6 8 1}$ \\
tF0_min & -0.081 & -0.396 & $-\mathbf{0 . 5 0 1}$ \\
call length & -0.257 & 0.145 & $-\mathbf{0 . 3 3 5}$ \\
range_F0 & -0.005 & -0.014 & $\mathbf{- 0 . 2 2 1}$ \\
\hline
\end{tabular}

The variables are ordered by absolute size of correlation within function. Largest absolute correlation between each variable and any discriminant function are indicated in bold. The extracted discriminant function(s) accounted for $78.1 \%$ of the variance

related stimuli than to eagle shrieks (pairwise comparison: leopard-eagle: $\beta=-6.247, \mathrm{SE}=2.173, d f=27, t=-2.875$, $p=0.0078$; leopard alarm-eagle: $\beta=-10.96, \mathrm{SE}=2.402$, $d f=27, t=-4.563, p=0.0001$ ), a pattern not observed in Taï (pairwise comparison: leopard-eagle: $\beta=1.103, \mathrm{SE}=0.779$, $d f=39, t=1.4145, p=0.1651$; leopard alarm-eagle: $\beta=-0.279, \mathrm{SE}=0.8552, d f=39, t=-0.3266, p=0.7456)$. Tiwai females also responded faster to male alarm calls than to corresponding original predator cues (pairwise comparison: leopard-leopard alarm: $\beta=-4.7127, \mathrm{SE}=2.173, d f=27$, $t=-2.169, p=0.0391$; eagle-eagle alarm: $\beta=-8.575$, $\mathrm{SE}=2.5, d f=27, t=-3.429, p=0.002)$. Again, this pattern was not observed in Taï (pairwise comparison: leopard-leopard alarm: $\beta=1.382, \mathrm{SE}=0.825, d f=39, t=1.675, p=0.1019$; eagle-eagle alarm: $\beta=-0.5817, \mathrm{SE}=0.8313, d f=39, t=-0.699$, $p=0.4882$ ).

For comparisons of the latencies to respond within habitats, the critical $\mathrm{p}$ value after Bonferroni correction was 0.0125 .

\section{Discussion}

Our results show that two populations of Diana monkeys differed significantly in their vocal behaviour and that these differences were best explained by differences in predation pressure between both habitats. We found no acoustic differences in alert calls and predator-specific alarm calls, but significant differences in call rates and call latencies. This suggests that the acoustic structure of female alarm and alert call is not affected by habitat differences. However, habitatspecific differences were observed in the latencies and frequencies of call production, suggesting that learning plays a role and that ecological factors can shape the vocal behaviour. In particular, Taï females who have considerable experience with leopards called more and responded faster than Tiwai females, who presumably had no previous experience with leopards.

Interestingly, these effects were not general, but limited to their leopard alarm calls and alert calls and did not affect the other call types. The strongest differences were observed to leopard growl playbacks. Tiwai females produced significantly fewer alert calls and leopard alarm calls and calls were emitted significantly later compared to Taï females. We assume that, with no prior experience with leopards, Tiwai females responded to leopard growls as an unspecific, loud and unknown disturbance, which triggered a slower, relatively weak and unspecific response. An alternative explanation is that calling behaviour of Tiwai females is the result of different individual backgrounds. The approximate life span of
Table 5 Descriptive statistics and tests of equality of groups' means between habitats for contact calls for all acoustic parameters that have been included in the Discriminant Function Analysis

Significant $p$ values are indicated in bold

\begin{tabular}{|c|c|c|c|c|c|c|c|}
\hline & \multicolumn{2}{|l|}{ mean } & \multicolumn{2}{|l|}{$\mathrm{SD}$} & \multirow[t]{2}{*}{ Wilks' $\lambda$} & \multirow[t]{2}{*}{$\mathrm{F}_{1,52}$} & \multirow[t]{2}{*}{$\mathrm{P}$} \\
\hline & Tiwai & Taї & Tiwai & Taï & & & \\
\hline mean_F0 & $2,850.7$ & $2,523.3$ & 512.3 & 555.3 & 0.918 & 4.6 & 0.036 \\
\hline max_F0 & 3672 & $2,975.5$ & 256.4 & 552.7 & 0.65 & 28 & $<0.001$ \\
\hline min_F0 & $1,848.7$ & $1,753.7$ & 598.4 & 566.5 & 994 & 0.335 & 0.565 \\
\hline range_F0 & $1,860.7$ & $1,221.7$ & 739.2 & 595.5 & 0.811 & 12.1 & 0.001 \\
\hline start_F0 & $2,501.6$ & $1,886.9$ & 781.4 & 558.2 & 0.821 & 11.3 & 0.001 \\
\hline mid_F0 & $3,307.8$ & $2,768.7$ & 495.2 & 675.7 & 0.844 & 9.6 & 0.003 \\
\hline end_F0 & $2,460.4$ & $2,243.4$ & 811.2 & 613.6 & 0.977 & 1.2 & 0.271 \\
\hline tF0_max & 0.17 & 0.11 & 0.06 & 0.03 & 0.745 & 17.8 & $<0.001$ \\
\hline $\mathrm{tF} 0 \_$min & 0.16 & 0.07 & 0.12 & 0.07 & 0.844 & 9.6 & 0.003 \\
\hline call length & 0.29 & 0.16 & 0.07 & 0.06 & 0.504 & 51.2 & $<0.001$ \\
\hline
\end{tabular}


Fig. 2 Composition of the vocal behaviour of female Diana monkeys at $\mathbf{a}$ Tiwai Island and $\mathbf{b}$ in Taï forest after listening to playbacks of original predators (leopard growls: $N_{\text {Tai }}=13$, $N_{\text {Tiwai }}=11$; and eagle shrieks: $N_{\text {Tai }}=11, N_{\text {Tiwai }}=7$ ) and corresponding male alarm calls (leopard alarm calls: $N_{\text {Taï }}=9$, $N_{\text {Tiwai }}=7$; and eagle alarm calls: $N_{\text {Taï }}=10, N_{\text {Tiwai }}=6$ ). Differently coloured proportions within stacked bars indicate the median call number per group for different call types. White parts: alert calls; light grey parts: eagle alarm calls; dark grey parts: contact calls; black parts: leopard alarm calls

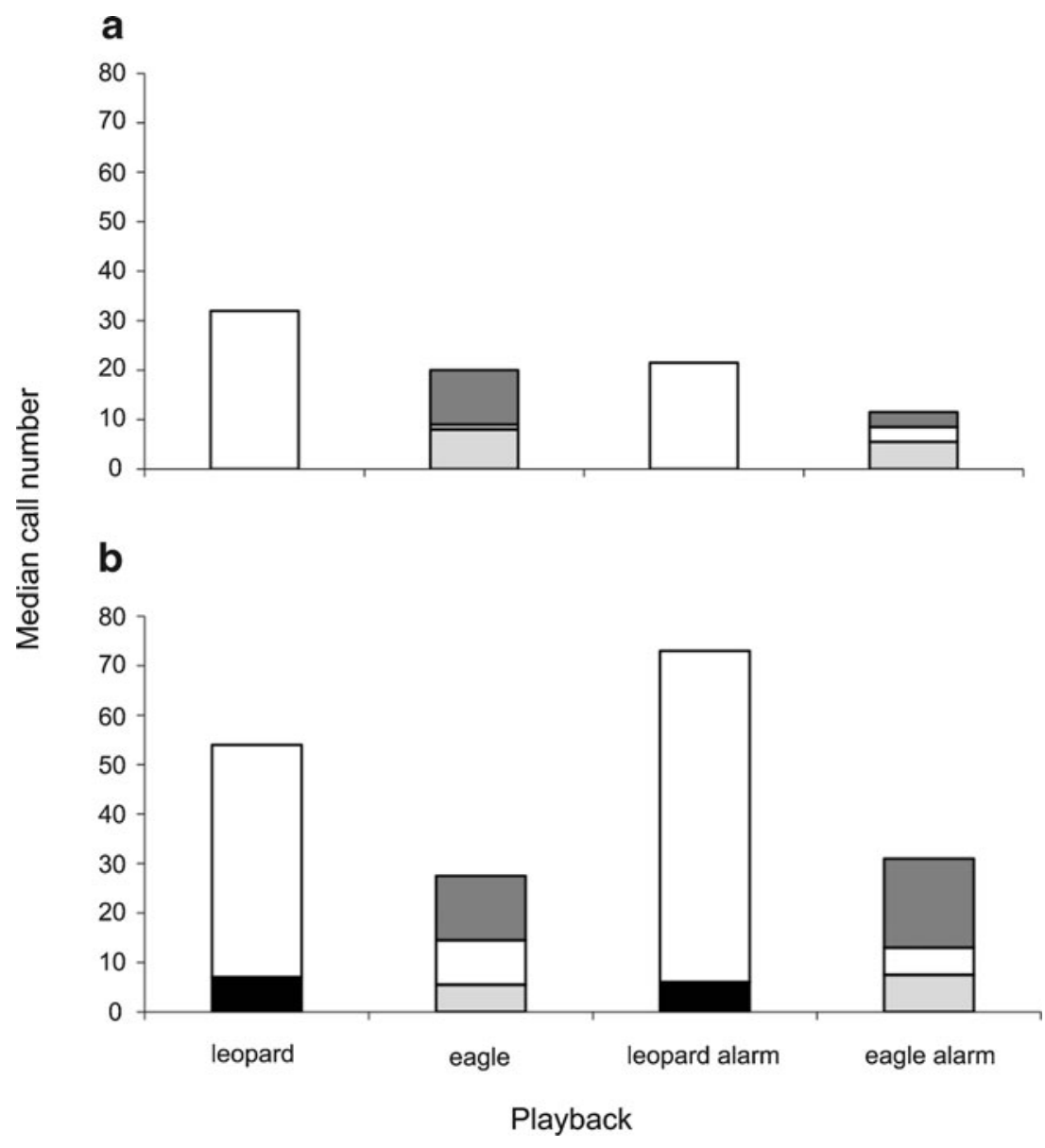

Diana monkeys has been estimated to about 20 years in the wild (Kappeler and Pereira 2003). Hence, it might well be that some of the older Tiwai females had some experience with leopards during infancy. It may have been that leopards were occasionally crossing the Moa River surrounding Tiwai
Island, before going locally extinct on the adjacent main land due to poaching and habitat fragmentation. If this was the case, then these individual differences should be reflected more explicitly on a population level over time with proportionally more females contributing to groups' vocal responses

Table 6 Median number of calls and statistical comparisons of call rates between the females of Taï forest and Tiwai Island in the first minute after the beginning of a playback (Mann-Whitney $U$-tests)

\begin{tabular}{|c|c|c|c|c|c|c|c|c|c|c|c|c|c|}
\hline \multirow[t]{3}{*}{ Playback } & \multirow[t]{3}{*}{$N$} & \multicolumn{12}{|l|}{ Call type } \\
\hline & & \multicolumn{3}{|c|}{ Eagle alarm } & \multicolumn{3}{|c|}{ Leopard alarm } & \multicolumn{3}{|c|}{ Alert call } & \multicolumn{3}{|c|}{ Contact call } \\
\hline & & Median & $U$ & $p$ & Median & $U$ & $p$ & Median & $U$ & $p$ & Median & $U$ & $p$ \\
\hline \multirow[t]{2}{*}{ Leopard growl } & $N_{\text {Tiwai }}=11$ & 0 & 75.0 & 1.0 & 0 & 36.0 & 0.031 & 32 & 25.0 & 0.004 & 0 & 62.0 & 0.495 \\
\hline & $N_{\text {Tаї }}=13$ & 0 & & & 7 & & & 47 & & & 0 & & \\
\hline \multirow[t]{2}{*}{ Eagle shriek } & $N_{\text {Tiwai }}=7$ & 8 & 30.5 & 0.172 & 0 & 42.0 & 0.636 & 1 & 18.5 & 0.02 & 11 & 38.5 & 0.443 \\
\hline & $N_{\text {Taï }}=11$ & 5.5 & & & 0 & & & 9 & & & 13 & & \\
\hline \multirow[t]{2}{*}{ Leopard alarm } & $N_{\text {Tiwai }}=7$ & 0 & 44.0 & 1.0 & 0 & 14.0 & 0.012 & 21.5 & 12.0 & 0.007 & 0 & 26.5 & 0.152 \\
\hline & $N_{\text {Taï }}=9$ & 0 & & & 6 & & & 67 & & & 0 & & \\
\hline \multirow[t]{2}{*}{ Eagle alarm } & $N_{\text {Tiwai }}=6$ & 5.5 & 13.0 & 0.181 & 0 & 24 & 1 & 3 & 12.5 & 0.142 & 3 & 10 & 0.081 \\
\hline & $N_{\text {Taï }}=10$ & 7.5 & & & 0 & & & 5.5 & & & 18 & & \\
\hline
\end{tabular}

Significant differences for each call type are indicated in bold 
Fig. 3 Latencies (s) of female vocal responses in Taï Forest (white boxes) and at Tiwai Island (grey boxes) for each playback stimulus. The bottom of the box indicates the first, the top of the box the third quartile. The horizontal line within the box represents the median. Whiskers include values that amount to 1.5 times the height of the box. Circles indicate outliers that do not fall in the inner fences (whiskers). Asterisks indicate extreme outliers and represent values more than three times the height of the box

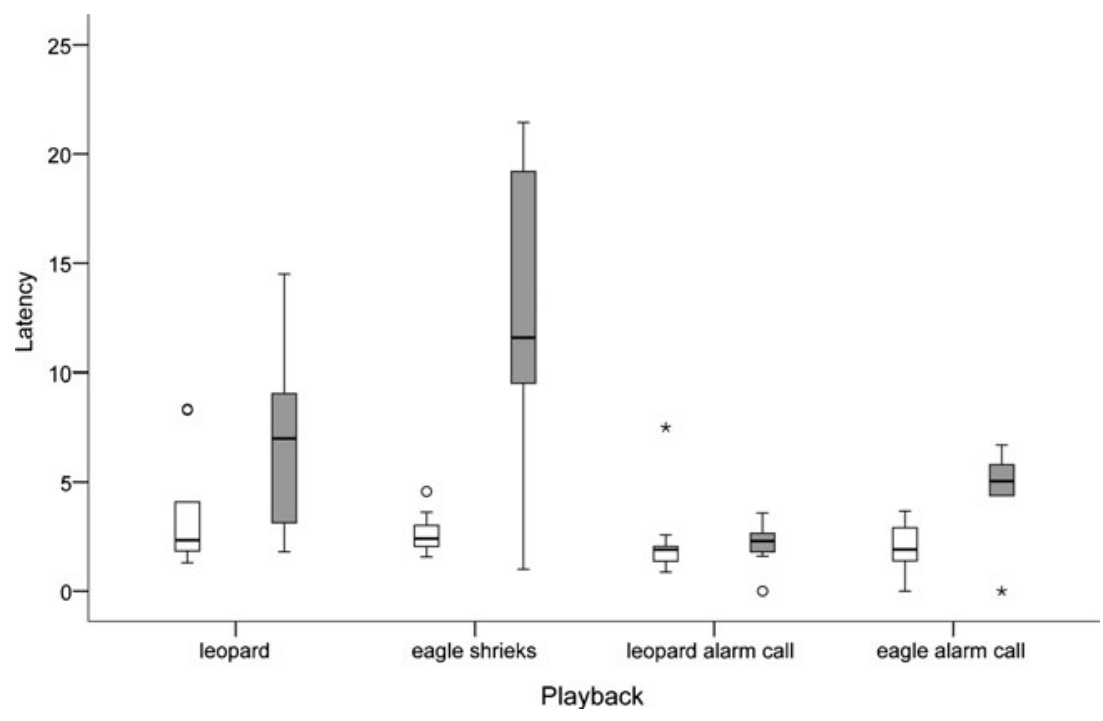

that had no leopard experience. Accordingly, it may be possible that leopard alarm calls will completely vanish from the repertoire of Tiwai females in the coming years.

Although females uttered the same number of eagle alarm calls in both habitats to eagle-related playbacks, we found Tiwai females to emit fewer alert calls to eagle shrieks compared to Taï females. Similarly, we found differences in the latencies to respond to eagle-related stimuli, with Tiwai females responding significant later than Taï females and Tiwai females also responding significant later to eagle shrieks than to all other playbacks. We can think of two explanations for these findings. First, it is possible that the hunting strategies of crowned eagles differ at the two sites in some relevant way, leading to different anti-predator strategies in the monkeys. Shultz and Thomsett (2007) suggested that crowned eagles could change their hunting strategy from solitary hunting by stealth and ambush to pursuit and cooperative hunting. Alert calls alone, unlike eagle alarm calls, are not predator-specific

Table 7 Comparison of latencies to respond to single playback stimuli between females in Taï Forest and at Tiwai Island (Mann-Whitney $U$ tests)

\begin{tabular}{lcccc}
\hline Playback & $N$ & Mean latency (s) & $U$ & $p$ \\
\hline Leopard growls & $N_{\text {Tiwai }}=11$ & 6.82 & 108 & $\mathbf{0 . 0 3 7}$ \\
& $N_{\text {Tai }}=13$ & 3.71 & & \\
Eagle shrieks & $N_{\text {Tiwai }}=7$ & 13.07 & 60 & $\mathbf{0 . 0 2 4}$ \\
& $N_{\text {Taï }}=11$ & 2.61 & & \\
Leopard alarms & $N_{\text {Tiwai }}=7$ & 2.11 & 38 & 0.536 \\
& $N_{\text {Tai }}=9$ & 2.33 & & \\
Eagle alarms & $N_{\text {Tiwai }}=6$ & 4.49 & 50.5 & $\mathbf{0 . 0 2 9}$ \\
& $N_{\text {Taï }}=10$ & 2.03 & & \\
\hline
\end{tabular}

Significant differences in latency to respond for each playback stimulus are indicated in bold and thus do not allow group members to infer eagle presence and to adjust their anti-predator behaviour appropriately. However, these calls are considerably more conspicuous and allow predators to locate calling individuals more easily than by contact calls, which function to maintain group cohesion and to coordinate group movement. This might explain the Tiwai female responses with same calling rates for close range contact calls and eagle alarm calls but with reduced alert call rates.

Second, differences in call rates might be due to local traditions caused by social learning. However, additional playback experiments are needed to address this more specifically (e.g., Seyfarth and Cheney 1990). In particular, it has then to be clarified why and how learning would impact on the adjustment of frequency parameters as for contact calls but on call rates for specific alarm calls.

Regarding contact calls, we found significant habitatspecific differences in frequency-related acoustic features. These gradual changes of acoustic parameters have been rarely found in primates so far (Janik and Slater 2000) and suggest some undocumented flexibility and potential for learning on the signaller. Interestingly, this has been found in a call type that has important social functions and is used in call exchanges between group members (Candiotti et al. 2012b). The mechanisms that lead to such subtle production learning are not really understood. Future studies will need to address the degree to which individuals have voluntary control over the acoustic features of these social calls.

In conclusion, our results show that different call types in female Diana monkeys' vocal repertoire are likely to be affected by ecological factors, i.e., predation. This further highlights the importance of predator experience on alarm calling behaviour and vocal flexibility in primates (Gil-da-Costa et al. 2003; Fichtel and Kappeler 2011). However, our data are somewhat inconsistent with the current notion that primate 
alarm-calling behaviour is completely 'hardwired' and unaffected by ontogenetic experience (Schel and Zuberbühler 2009). However, the factors that impact on monkeys' alarm calling behaviour might be relatively complex, as indicated by different responses to eagle shrieks in the present study. Differences in predator behaviour, alarm calling by other species, or within group effects might provide potential explanations and grounds for further investigation.

When comparing our results to the previously reported effects on males' vocal behaviour (Stephan and Zuberbühler 2008), we found that males showed differences in how individual call units were arranged into sequences, while females mainly differed in how they used their vocal repertoires. How these differences between the sexes relate to general differences in the function of vocal behaviour and in the underlying cognitive processes remains to be investigated.

Acknowledgments The study was funded by the ESF's 'Origins of Man, Language and Languages' programme, the EC's FP6 'What it means to be human' and the Leverhulme Trust. In Ivory Coast, we thank the 'Ministère de la Recherche Scientifique', the 'Ministère de l'Agriculture et des Ressources Animales' and PACPNT for permission to conduct research in the Taï National Park. In Sierra Leone, we thank the Environmental Foundation for Africa for permission to conduct research, and K. Koroma, M. Maguna and D. Grüsser for their help. We are grateful to Benjamin D. Charlton for providing the PRAAT script that had just to be modified according to this species specifications and $\mathrm{H}$. Nobis for valuable comments and discussion.

Ethical standards All experiments reported here have been conducted in accordance with the current laws in Sierra Leone and Ivory Coast. Permission for research was given by the 'Ministère de la Recherche Scientifique' and the 'Ministère de l'Agriculture et des Ressources Animales' in Ivory Coast as well as by the Environmental Foundation for Africa in Sierra Leone.

\section{References}

Arnold K, Zuberbühler K (2006) Language evolution: semantic combinations in primate calls. Nature 441:303-339

Arnold K, Zuberbühler K (2008) Meaningful call combinations in a nonhuman primate. Curr Biol 18:202-203

Bouchet H, Blois-Heulin C, Lemasson A (2012) Age- and sex-specific patterns of vocal behavior in De Brazza's monkeys (Cercopithecus neglectus). Am J Primatol 74:12-28

Bshary R, Noë R (1997) Red colobus and Diana monkeys provide mutual protection against predators. Anim Behav 54:1461-1474

Buzzard P, Eckardt W (2007) Social systems of the Taï Guenons (Cercopithecus spp.). In: McGraw S, Zuberbühler K, Noë R (eds) Monkeys of the Taï forest: an African monkey community. Cambridge University Press, Cambridge, pp 51-71

Candiotti A, Zuberbühler K, Lemasson A (2012a) Context-related call combinations in female Diana monkeys. Anim Cogn 15:327-339

Candiotti A, Zuberbühler K, Lemasson A (2012b) Convergence and divergence in Diana monkey vocalizations. Biol Lett 8:382-385

Fichtel C, Kappeler PM (2011) Variation in the meaning of alarm calls in Verreaux's and Coquerel's sifakas (Propithecu sverreauxi, $P$. coquereli). Int J Primatol 32:346-361
Fitch WT (2005) The evolution of language: a comparative review. Biol Philos 20:193-230

Fitch WT (2010) The evolution of language. Cambridge University Press, Cambridge

Gil-da-Costa R, Palleroni A, Hauser MD, Touchton J, Kelley JP (2003) Rapid acquisition of an alarm response by a neotropical primate to a newly introduced avian predator. Proc Roy Soc Lond B 270:605-610

Hill CM (1994) The role of female diana monkeys, Cercopithecus diana, in territorial defence. Anim Behav 47:425-431

Höner OP, Leumann L, Noë R (1997) Dyadic associations of red colobus and Diana monkey groups in the Taï National Park, Ivory Coast. Primates 38:281-291

Janik VM, Slater PJB (1997) Vocal learning in mammals. Adv Stud Behav 26:59-99

Janik VM, Slater PJB (2000) The different roles of social learning in vocal communication. Anim Behav 60:1-11

Kappeler PM, Pereira ME (2003) Primate life histories and socioecology. Chicago University Press, Chicago

Lemasson A, Ouattara K, Bouchet H, Zuberbühler K (2010) Speed of call delivery is related to context and caller identity in Campbell's monkey males. Naturwissenschaften 97:1023-1027

McGraw WS (2007) Positional behavior and habitat use of Taï forest monkeys. In: McGraw WS, Zuberbühler K, Noë R (eds) Monkeys of the Taï forest: an African monkey community. Cambridge University Press, Cambridge, pp 223-253

Murphy D, Lea SEG, Zuberbühler K (2013) Male blue monkey alarm calls encode predator type and distance. Anim Behav 85:119-125

Oates JF, Whitesides GH, Davies AG, Waterman PG, Green SM, Dasilva GL, Mole S (1990) Determinants of variation in tropical forest primate biomass: new evidence from West Africa. Ecology 71:328-343

Owren MJ, Dieter JA, Seyfarth RM, Cheney DL (1993) Vocalizations of rhesus (Macaca mulatta) and Japanese (M. fuscata) macaques cross-fostered between species show evidence of only limited modification. Dev Psychobiol 26:389-406

Papworth S, Böse AS, Barker J, Zuberbühler K (2008) Male blue monkeys alarm call in response to danger experienced by others. Biol Lett 4:472-475

Poole JH, Tyack PL, Stoeger-Horwath AS, Watwood S (2005) Elephants are capable of vocal learning. Nature 434:455-456

Rowell TE (1988) The social system of guenons, compared with baboons, macaques and mangabeys. In: Gautier-Hion A, Bourlière F, Gautier JP, Kingdon J (eds) A primate radiation: evolutionary biology of the African guenons. Cambridge University Press, Cambridge, pp 439-451

Schel AM, Zuberbühler K (2009) Responses to leopards are independent of experience in Guereza colobus monkeys. Behaviour 146:1709 1737

Schustermann RJ (2008) Vocal learning in mammals with special emphasis on pinnipeds. In: Oller DK, Griebel U (eds) The evolution of communicative flexibility: complexity, creativity, and adaptability in human and animal communication. MIT Press, Cambridge

Seyfarth RM, Cheney DL (1986) Vocal development in vervet monkeys. Anim Behav 34:1640-1658

Seyfarth RM, Cheney DL (1990) The assessment by vervet monkeys of their own and another species' alarm calls. Anim Behav 40:754-764

Seyfarth RM, Cheney DL (2003) Signalers and receivers in animal communication. Annu Rev Psychol 54:145-173

Seyfarth RM, Cheney DL, Bergman TJ (2005) Primate social cognition and the origins of language. Trends Cogn Sci 9:264-266

Shultz S, Thomsett S (2007) Interactions between African crowned eagles and their primate prey community. In: McGraw WS, Zuberbühler K, Noë R (eds) Monkeys of the Taï forest: an African monkey community. Cambridge University Press, Cambridge

Snowdon CT (2009) Plasticity of communication in nonhuman primates. In: Naguib M, Janik VM (eds) Advances in the study of behavior. Academic Press, Burlington, pp 239-276 
Stephan C, Zuberbühler K (2008) Predation increases acoustic complexity in primate alarm calls. Biol Lett 4:641-644

Stephan C, Bugnyar T (2013) Pigeons integrate past knowledge across sensory modalities. Anim Behav 85:605-613

Stoeger AS, Mietchen D, Oh S, de Silva S, Herbst CT, Kwon S, Fitch WT (2012) An Asian elephant imitates human speech. Curr Biol 22:1-5

Todd P, Macdonald C, Coleman D (2008) Within-group differences in captive Diana monkey (Cercopithecus diana diana) behaviour. $\mathrm{J}$ Ethol 26:273-278

Townsend SW, Zöttl M, Manser MB (2011) All clear? Meerkats attend to contextual information in close calls to coordinate vigilance. Behav Ecol Sociobiol 65:1927-1934

Uster D, Zuberbühler K (2001) The functional significance of Diana monkey 'clear' calls. Behaviour 138:741-756

Whitesides GH, Oates JF, Green S, Kluberdanz RP (1988) Estimating primate densities from transects in a West African rainforest: a comparison of techniques. J Anim Ecol 57:345-367
Wich SA, Nunn CL (2002) Do male "loud calls" function in mate defense? A comparative study of long-distance calls in primates. Behav Ecol Sociobiol 52:474-484

Winter P, Handley P, Ploog D, Schott D (1973) Ontogeny of squirrel monkey calls under normal conditions and under acoustic isolation. Behaviour 47:230-239

Zuberbühler K (2000a) Referential labelling in Diana monkeys. Anim Behav 59:917-927

Zuberbühler K (2000b) Causal cognition in a non-human primate: field playback experiments with Diana monkeys. Cognition 76:195-207

Zuberbühler K (2002) Effects of natural and sexual selection and the evolution of guenon loud calls. In: Glenn ME, Cords M (eds) The guenons. Diversity and adaptation in African monkeys. Kluwer Academic Publishers, New York, pp 289-306

Zuberbühler K, Noë R, Seyfarth RM (1997) Diana monkey long-distance calls: messages for conspecifics and predators. Anim Behav 53: 589-604 